\title{
Efeito da Diluição Sobre a Microestrutura da Liga AWS ER NiCrMo-14 na Soldagem de Revestimentos pelo Processo TIG com Alimentação de Arame Frio
}

\author{
Émerson Mendonça Miná ${ }^{1}$, Yuri Cruz da Silva ${ }^{1}$, Jean Dille ${ }^{2}$, Cleiton Carvalho Silva ${ }^{1}$ \\ 1 Universidade Federal do Ceará - UFC, Departamento de Engenharia Metalúrgica e de Materiais, Fortaleza, CE, Brasil. \\ 2 Université Libre de Bruxelles, Matters and Materials Department, Brussels, Belgium.
}

Recebido: 19 Fev., 2016

Aceito: 01 Ago., 2016

E-mails: emina@metalmat.ufc.br (EMM), jdille@ulb.ac.be (JD)
Resumo: A diluição é um evento de forte influência na microestrutura e, consequentemente, nas propriedades de revestimentos soldados. O presente estudo avaliou o efeito do nível de diluição na microestrutura da zona fundida de revestimentos da liga Inconel 686. Os revestimentos foram depositados por processo TIG com alimentação de arame frio. A diluição foi calculada a partir das características geométricas dos revestimentos e por medidas de composição química de EDS e de espectroscopia de emissão ótica. As microestruturas de todos os revestimentos foram compostas por uma matriz $\gamma$-CFC com alguns precipitados secundários. Essas partículas são chamadas de fases topologicamente compactas. Esses precipitados assumiram diversos aspectos morfológicos, nos quais os precipitados com morfologia disforme foram observados com maior frequência em todos os revestimentos avaliados, independentemente do nível de diluição. Uma fase com morfologia lamelar, que estabelece uma relação de orientação com a matriz Y-CFC na direção de solidificação, foi observada nos revestimentos de menor diluição. Além disso, uma fase com morfologia disforme com uma fina precipitação agregada foi observada nos revestimentos mais diluídos.

Palavras-chave: TIG; Liga de níquel; Inconel 686; Diluição; Microestrutura.

\section{Effect of Dilution on the Microstructure of AWS ER NiCrMo-14 Weld Overlay Deposited by TIG Cold Wire Feed Process}

\begin{abstract}
The dilution is an event that have a high influence on the microstructure and, consequently, in the properties of weld claddings. The present study evaluated the effect of dilution level on the microstructure of the fusion zone of alloy Inconel 686 weld claddings. The claddings were welded by the TIG cold wire feed process. The dilution was calculated from the geometric characteristics and based on chemical composition of the materials obtained by energy dispersive X-ray spectroscopy and optical emission spectroscopy. The microstructure of all claddings were composed by a $\mathrm{y}$-FCC matrix with some minor precipitates. These particles are called in literature as topologically closed-packed phases (TCP). These precipitates assumed several morphological aspects, being the shapeless morphology observed in more frequency in all claddings evaluated, independent of dilution level. A phase with lamellar morphology, which growth establishing an orientation relationship with the $\gamma$-FCC matrix solidification direction, was observed only in claddings with a low dilution level. In addition, a shapeless phase with a fine precipitation aggregated was observed in claddings with a high dilution level.
\end{abstract}

Key-words: TIG; Nickel alloy; Inconel 686; Dilution; Microstructure.

\section{Introdução}

A liga Inconel 686 pertence ao grupo das superligas de níquel e destaca-se pela elevada resistência à corrosão localizada. Isto se deve à elevada concentração dos elementos $\mathrm{Cr}$, Mo e W, que são responsáveis por manter a integridade da liga mesmo em ambientes de elevada agressividade corrosiva. É uma liga pertencente à terceira geração das superligas de níquel e foi desenvolvida em 1992 para suprir a necessidade de aplicações, as quais requeriam elevada resistência à corrosão, já que as principais superligas anteriormente utilizadas (ligas 625, C-276 e C-22) não atendiam às severas condições de serviço [1]. Por esse motivo, a liga Inconel 686 vem sendo utilizada em aplicações nas indústrias do petróleo e gás, onde é comum que os seus equipamentos e componentes estejam operando nas mais adversas condições de serviço (altas temperaturas, elevada pressão, fluidos corrosivos, etc.).
Este é um artigo publicado em acesso aberto (Open Access)
sob a licença Creative Commons Attribution Non-Commerci que permite uso, distribuição e reprodução em qualquer meio, sem restriçōes desde que sem fins comerciais e que 0 trabalho original seja corretamente citado. 
A aplicação das superligas de níquel de forma maciça implica em um elevado custo, o que dificulta o seu uso para muitas aplicações sob o ponto de vista econômico [2,3]. A liga Inconel 686, por sua vez, é relativamente mais cara que as demais superligas de níquel da categoria das ligas endurecíveis por solução sólida projetadas para resistir a diversos meios corrosivos. Este maior valor agregado é referente a elevada adição de elementos de liga, em especial o $\mathrm{Cr}$ e o Mo, bem como o baixo teor de Fe presente na liga. Estudos relatam que em determinados meios corrosivos a liga Inconel 686 apresenta uma resistência à corrosão superior às demais superligas da mesma classe [4]. Portanto, apesar do alto investimento empregado, ainda assim a liga Inconel 686 se torna atrativa, já que é possível fabricar equipamentos e componentes mais resistentes a ação corrosiva. Contudo, conforme já destacado, produzir equipamentos e componentes utilizando apenas superligas níquel elevaria de forma excessiva os custos de qualquer projeto. Neste contexto, a soldagem de revestimentos apresenta-se como uma alternativa viável para a fabricação de peças e equipamentos, nas quais as superfícies externas ou internas necessitam de propriedades especificas que proporcionem um desempenho satisfatório às suas condições de serviço [3].

Apesar das vantagens associadas à utilização da soldagem, a fabricação de tais revestimentos requer atenção a diversos aspectos metalúrgicos que tornam a prática extremamente complexa. A estrutura cristalina do substrato e do depósito, bem como as suas respectivas propriedades, devem ser levadas em consideração na escolha dos materiais [5]. Além disso, as diversas alterações microquímicas por consequência da diluição do depósito com o substrato [6], podem causar alterações significativas na microestrutura do revestimento, podendo por exemplo, favorecer a nucleação de fases secundárias, bem como o aumento ou dissolução do volume de fases deletérias por consequência do reaquecimento entre os passes dos revestimentos.

No entanto, poucos relatos relacionados à liga Inconel 686 foram publicados até o presente momento, principalmente trabalhos que destaquem a sua microestrutura como soldada. Atualmente, estudos vêm sendo desenvolvidos no Laboratório de Pesquisa e Tecnologia em Soldagem (LTPS) da Universidade Federal do Ceará (UFC) com o objetivo de avaliar o desempenho da liga Inconel 686 visando a sua aplicação na indústria do petróleo e gás $[4,7,8]$. $O$ presente estudo investigou a microestrutura da liga Inconel 686 depositada na forma de arame AWS ER NiCrMo-14 sobre um aço estrutural com diversos níveis de diluição, observando as possíveis alterações na microestrutura.

\section{Procedimento Experimental}

\subsection{Materiais}

Para a soldagem dos revestimentos foi utilizado como depósito o arame AWS ER-NiCrMo-14 com 1,2 mm de diâmetro, que por sua vez apresenta as mesmas especificações compatíveis com as da liga Inconel 686 . 0 substrato utilizado foi o aço estrutural ASTM A36. A Tabela 1 apresenta a composição química dos materiais utilizados. Para a fabricação dos revestimentos foi utilizado o processo TIG com alimentação de arame frio. Foi utilizado um eletrodo de tungstênio toriado com $4 \mathrm{~mm}$ de diâmetro. $O$ gás de proteção utilizado foi o argônio puro.

Tabela 1. Composição química do metal de adição e metal de base (\% em peso).

\begin{tabular}{lcccccccc}
\hline \multicolumn{1}{c}{ Liga } & \multicolumn{7}{c}{ Composição química } \\
AWS ER-NiCrMo-14 & $\mathrm{Cr}$ & $\mathrm{Mo}$ & $\mathrm{W}$ & $\mathrm{Si}$ & $\mathrm{Fe}$ & $\mathrm{C}$ & $\mathrm{Mn}$ & $\mathrm{Ni}$ \\
(Inconel 686) & 20,53 & 16,39 & 3,97 & 0,06 & 0,29 & 0,01 & 0,23 & 58,52 \\
\hline ASTM A36 & $\mathrm{Cr}$ & $\mathrm{Mo}$ & $\mathrm{Al}$ & $\mathrm{Si}$ & $\mathrm{Fe}$ & $\mathrm{C}$ & $\mathrm{Mn}$ & $\mathrm{Ni}$ \\
& 0,02 & - & 0,03 & 0,09 & 98,94 & 0,23 & 0,67 & 0,02 \\
\hline
\end{tabular}

\subsection{Métodos}

Foi utilizado um robô industrial com um deslocamento automático da tocha TIG em conjunto com um cabeçote de alimentação automática de arame. Além disso, também foi utilizado um sistema de alinhamento e posicionamento do arame com relação ao arco elétrico, no qual manteve à adição de arame posicionada na frente do arco com sentido oposto a velocidade de soldagem, direcionando o arame para o centro do plasma com um ângulo de inserção de $60^{\circ}$ com relação ao plano normal da chapa de aço. Associado à fonte, foi utilizado um sistema de aquisição de dados para monitoramento da corrente e da tensão. 
Efeito da Diluição Sobre a Microestrutura da Liga AWS ER NiCrMo-14 na Soldagem de Revestimentos pelo Processo TIG com Alimentação de Arame Frio

Os revestimentos foram produzidos com uma tensão de $21 \mathrm{~V}$, corrente de $380 \mathrm{~A} \mathrm{e} \mathrm{uma} \mathrm{velocidade} \mathrm{de} \mathrm{soldagem}$ de $21 \mathrm{~cm} / \mathrm{min}$. Não foi utilizada temperatura de preaquecimento. Para a execução da soldagem multipasses, foi utilizado um deslocamento de $2 / 3$ a partir da posição inicial do primeiro passe para definir a posição de início do passe seguinte. Além disso, foi utilizado uma temperatura de interpasses de $100{ }^{\circ} \mathrm{C}$. A grande maioria dos parâmetros utilizados foram extraídos de trabalhos já publicados na literatura [7].

A velocidade de alimentação de arame (Valim) foi reduzida de uma amostra para a outra, a fim de obter níveis crescentes de diluição [9-11]. A Figura 1 ilustra os tipos de tecimento utilizados, espiral e triangular [12,13]. A amplitude do tecimento (AT) também variou em função do tipo de tecimento de $8 \mathrm{~mm}$ para $6 \mathrm{~mm}$. A Tabela 2 apresenta as condições de soldagem e os seus respectivos parâmetros de velocidade de alimentação de arame e de tecimento.

\section{(a) Espiral}

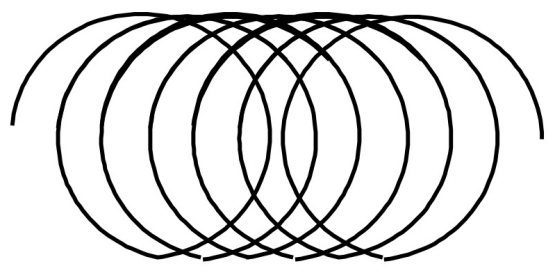

(b) Triangular

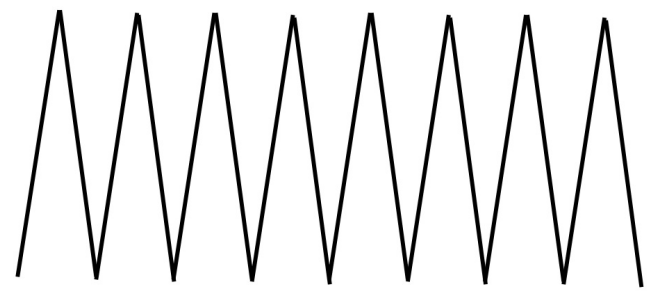

Figura 1. Ilustra a trajetória dos tipos de tecimento utilizado: (a) espiral e (b) triangular [13].

Tabela 2. Revestimentos e os seus respectivos parâmetros de soldagem. Valim representa a velocidade de alimentação de arame. AT representa a amplitude do tecimento.

\begin{tabular}{cccc}
\hline Revestimentos & Valim & Tecimento & AT \\
E85 & $8,5 \mathrm{~m} / \mathrm{min}$ & Espiral & $6 \mathrm{~mm}$ \\
T85 & $8,5 \mathrm{~m} / \mathrm{min}$ & Triangular & $8 \mathrm{~mm}$ \\
T75 & $7,5 \mathrm{~m} / \mathrm{min}$ & Triangular & $8 \mathrm{~mm}$ \\
T65 & $6,5 \mathrm{~m} / \mathrm{min}$ & Triangular & $8 \mathrm{~mm}$ \\
T55 & $5,5 \mathrm{~m} / \mathrm{min}$ & Triangular & $8 \mathrm{~mm}$ \\
T45 & $4,5 \mathrm{~m} / \mathrm{min}$ & Triangular & $8 \mathrm{~mm}$ \\
\hline
\end{tabular}

Os revestimentos foram cortados e passaram por uma preparação metalográfica convencional, especifica para viabilizar a obtenção das macrografia das seções transversais, bem como para as análises de microscopia eletrônica de varredura (MEV). Para o ensaio macrográfico, os revestimentos foram cortados na seção transversal e em seguida a superfície foi preparada com lixas de 100 e 220 mesh e posteriormente atacada com uma solução de $5 \%$ de ácido nítrico em álcool. Já para observar as microestruturas no MEV, as seções transversais dos revestimentos foram lixadas de 100 a 1200 mesh e polidas com partículas abrasivas de $3 \mu \mathrm{m}$ e $1 \mu \mathrm{m}$. A microestrutura do substrato foi atacada com uma solução de $2 \%$ de ácido nítrico em álcool (nital $2 \%$ ), já para a zona fundida foi aplicado um ataque eletrolítico utilizando uma tensão de $2 \mathrm{~V}$ por 20 segundos em uma solução aquosa de $10 \%$ de ácido crômico. Foram utilizados os microscópios eletrônico de varredura (MEV) FEI Quanta 3D do laboratório 4MAT da Universidade Livres de Bruxelas e o FEI Quanta FEG 450 da Central Analítica da Universidade Federal do Ceará (UFC).

Foram utilizadas duas metodologias para a obtenção da diluição dos revestimentos. No primeiro método foram utilizadas as características geométricas dos revestimentos, ou seja, a área do metal de base $\left(A_{M B}\right)$ e a do metal de adição $\left(A_{M A}\right)$ que compõem a zona fundida. A Equação 1 apresenta a fórmula utilizada para a realização do cálculo, na qual $D_{g}$ representa a diluição geométrica em percentual (\%). Foram utilizadas as medidas de duas 
seções transversais de cada revestimento e, por fim, realizada uma média da diluição dos revestimentos. A Figura 2 apresenta uma das macrografias utilizadas no cálculo da diluição geométrica.

$$
D_{g}=\frac{A_{M B}}{A_{M B}+A_{M A}} \times 100
$$

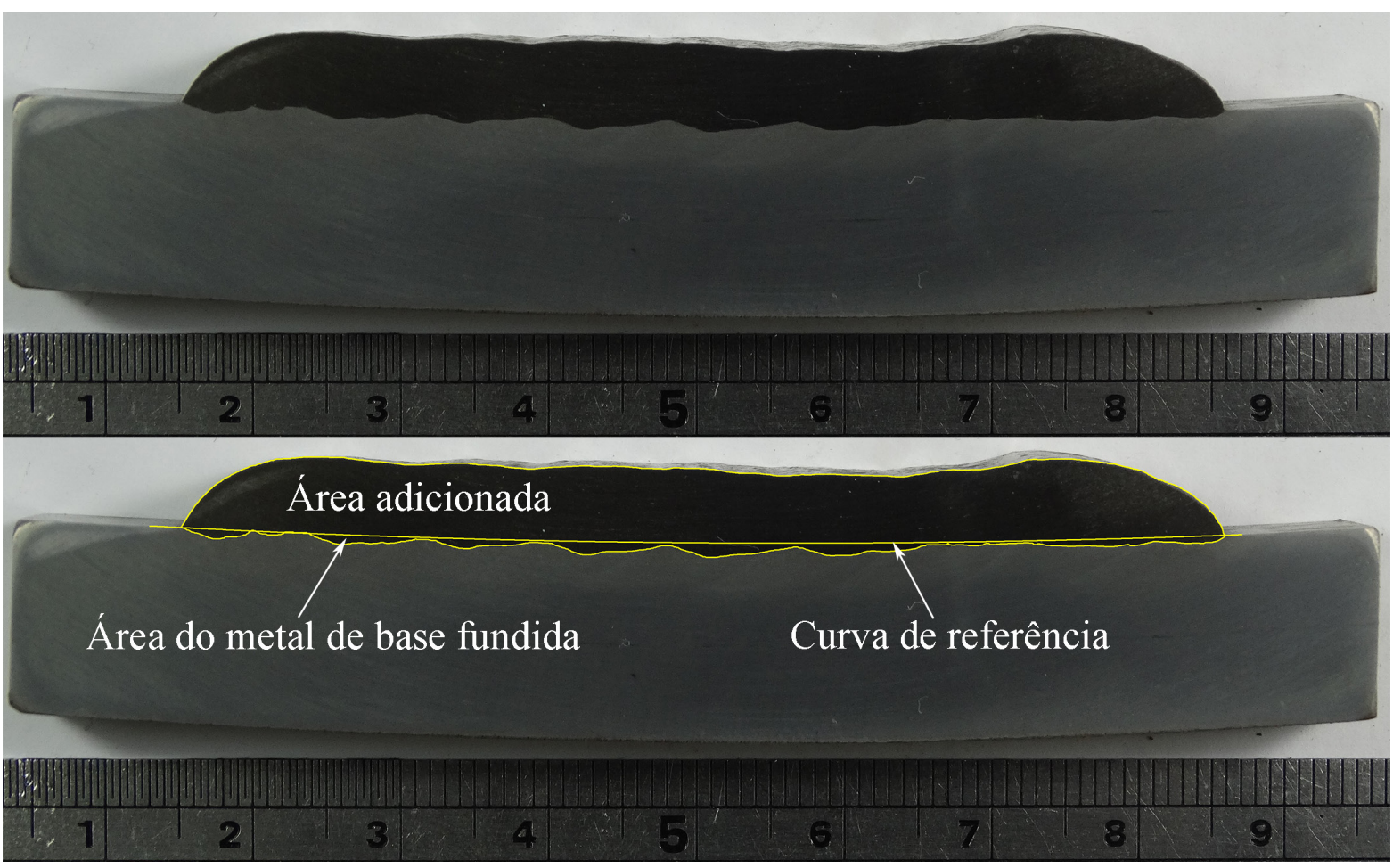

Figura 2. Macrografia da seção transversal do revestimento E85 e a sua respectiva análise geométrica.

O segundo método de avaliação da diluição, leva em consideração a concentração de Fe presente na zona fundida e compara com a concentração de Fe no metal de base e no metal de adição. Portanto, foi utilizada a concentração do Fe presente tanto na zona fundida $\left(C_{Z M}\right)$, como no metal de base $\left(C_{M B}\right)$ e no metal de adição $\left(C_{M A}\right)$. Foram realizadas 3 medidas de EDS em áreas da zona fundida, a fim de obter a composição química global dos revestimentos. A Equação 2 descreve a fórmula utilizada neste método, cuja $D_{E D S}$ representa a diluição por EDS em percentual (\%). A Figura 3 apresenta uma micrografia utilizada para medir a composição química global através de análises de EDS em área.

$$
D_{E D S}=\frac{C_{Z F}-C_{M A}}{C_{M B}-C_{M A}} \times 100
$$

\section{Resultados e Discussão}

\subsection{Diluição}

A Tabela 3 apresenta a média e o desvio padrão dos resultados da diluição geométrica e a da diluição por medidas de composição química por EDS. A Figura 4 apresenta uma regressão linear com os valores médios da diluição de cada revestimento para os dois métodos utilizados. A regressão linear apontou uma correlação entre os dois métodos de avaliação da diluição. 
Efeito da Diluição Sobre a Microestrutura da Liga AWS ER NiCrMo-14 na Soldagem de Revestimentos pelo Processo TIG com Alimentação de Arame Frio

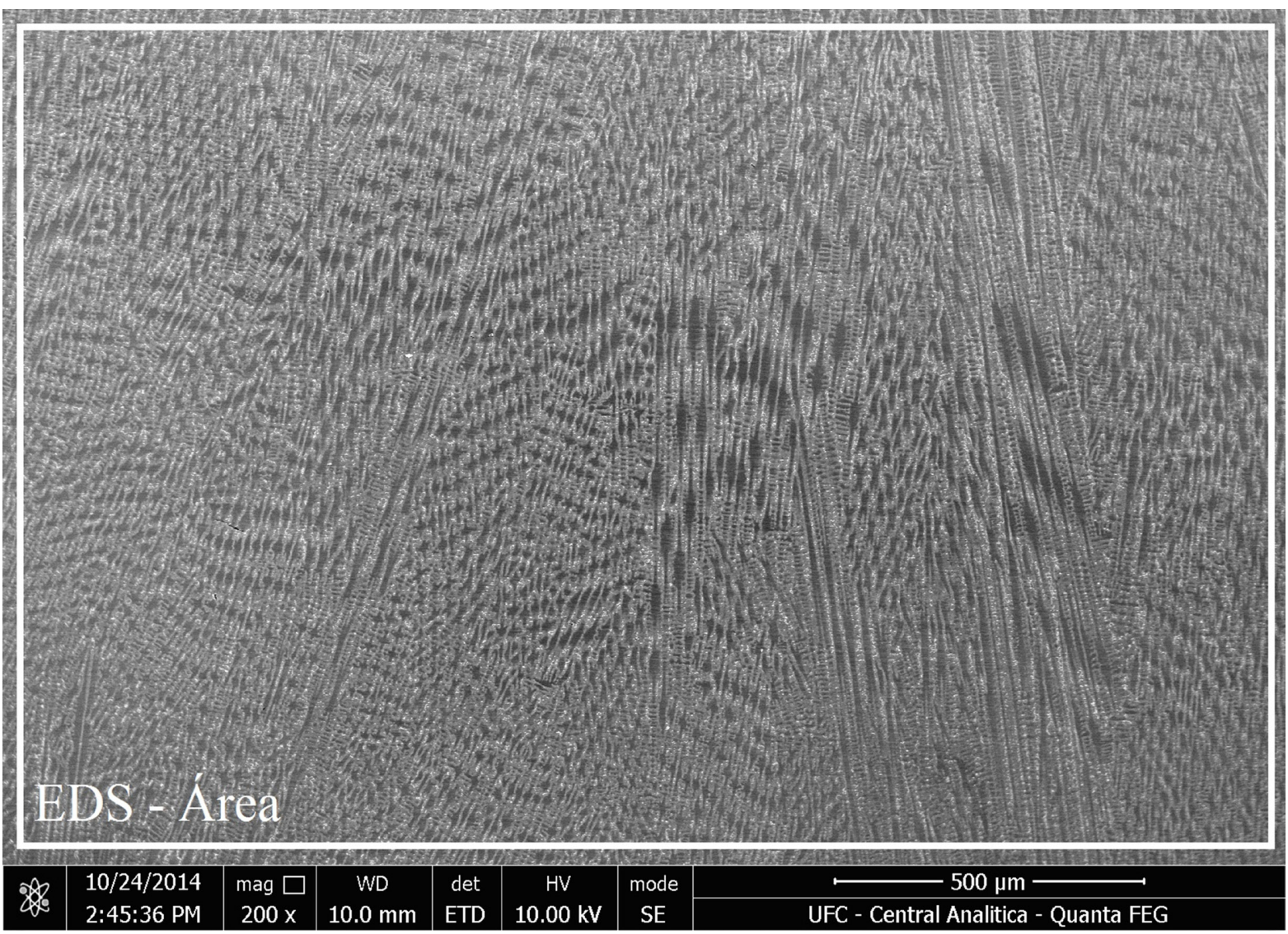

Figura 3. Micrografia de uma dada área selecionada para a varredura de composição química de EDS (\% em peso) da zona fundida do revestimento T85.

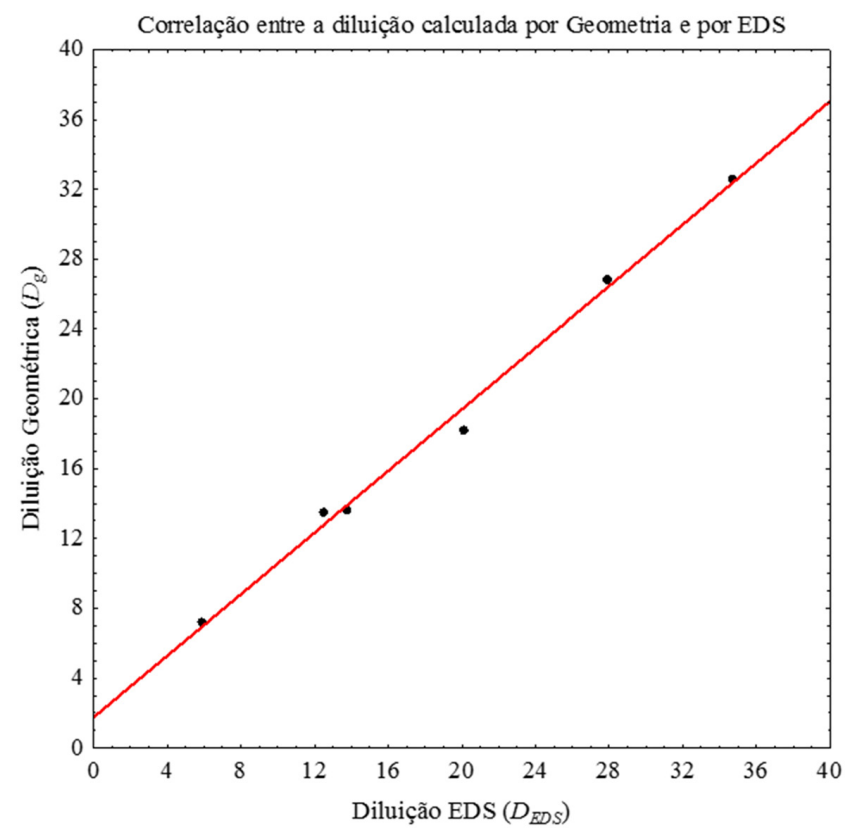

Figura 4. Correlação entre a diluição calculada utilizando as características geométricas do revestimento e por medidas de composição química por EDS. 
Tabela 3. Diluição geométrica e por concentração química dos revestimentos.

\begin{tabular}{ccc}
\hline Revestimentos & Diluição Geométrica $\left(D_{g}\right)$ & Diluição EDS $\left(D_{E D S}\right)$ \\
E85 & $7,2 \% \pm 0,5$ & $5,9 \% \pm 0,7$ \\
T85 & $13,5 \% \pm 0,8$ & $12,5 \% \pm 0,4$ \\
T75 & $13,6 \% \pm 0,7$ & $13,8 \% \pm 0,9$ \\
T65 & $18,2 \% \pm 1,4$ & $20,1 \% \pm 0,6$ \\
T55 & $26,8 \% \pm 2,6$ & $27,9 \% \pm 1,2$ \\
T45 & $32,6 \% \pm 0,7$ & $34,7 \% \pm 0,2$ \\
\hline
\end{tabular}

A diluição foi menor para o revestimento depositado com o tecimento espiral. Um resultado semelhante foi observado por Silva [7], no qual o autor destacou que o tecimento espiral promove uma intensa movimentação da poça de fusão, deslocando-se periodicamente para regiões mais frias da chapa e, desse modo, dissipando mais calor quando comparado ao tecimento triangular.

A diluição aumentou conforme a velocidade de alimentação de arame foi reduzida. Este fenômeno já foi relatado em outros estudos, e está relacionado ao menor volume de metal a ser fundido pela mesma energia de soldagem [9-11]. Além disso, este volume menor de arame adicionado reduz a barreira entre o substrato e o arco elétrico, desse modo, permitindo a fusão de uma maior fração do metal de base [11].

\subsection{Microestrutura}

As composições químicas dos revestimentos apresentaram alterações por consequência da diluição do depósito (liga Inconel 686) com o substrato (liga ASTM A36). Portanto, conforme o nível de diluição foi acrescido, a concentração de Fe aumentou em níveis quase que proporcionais. Este resultado já era esperado, uma vez que o metal de base é um aço carbono com uma composição química composta basicamente por Fe. Ainda como consequência ao aumento da diluição, a concentração dos principais elementos de liga ( $\mathrm{Ni}, \mathrm{Cr}, \mathrm{Mo} \mathrm{e} \mathrm{W)} \mathrm{caíram.}$ A Tabela 4 apresenta a média e o desvio padrão das medidas de composição química de EDS da zona fundida.

Tabela 4. Composição química de EDS (\% em peso) da zona fundida dos revestimentos.

\begin{tabular}{crrrrrr}
\hline Elementos & \multicolumn{1}{c}{ E85 } & T85 & T75 & T65 & T55 & T45 \\
Cr & $20,2 \pm 0,1$ & $16,9 \pm 0,2$ & $17,3 \pm 0,2$ & $18,4 \pm 0,1$ & $16,6 \pm 0,3$ & $14,3 \pm 0,0$ \\
Fe & $5,8 \pm 0,7$ & $12,3 \pm 0,4$ & $13,6 \pm 0,9$ & $19,9 \pm 0,6$ & $27,5 \pm 0,5$ & $34,3 \pm 0,2$ \\
Ni & $54,4 \pm 0,5$ & $54,3 \pm 0,3$ & $52,5 \pm 0,6$ & $48,0 \pm 0,5$ & $43,1 \pm 0,7$ & $37,7 \pm 0,0$ \\
Mo & $14,9 \pm 0,1$ & $12,5 \pm 0,1$ & $12,7 \pm 0,2$ & $10,7 \pm 0,1$ & $9,8 \pm 0,2$ & $10,3 \pm 0,2$ \\
W & $4,2 \pm 0,0$ & $3,6 \pm 0,1$ & $3,6 \pm 0,1$ & $2,6 \pm 0,0$ & $2,4 \pm 0,1$ & $3,1 \pm 0,1$ \\
Mn & $0,3 \pm 0,0$ & $0,3 \pm 0,1$ & $0,2 \pm 0,2$ & $0,4 \pm 0,0$ & $0,5 \pm 0,0$ & $0,4 \pm 0,0$ \\
\hline
\end{tabular}

Apesar das grandes alterações microquímicas, as zonas fundidas dos revestimentos apresentaram uma microestrutura semelhante ao já relatado em estudos que utilizaram depósitos de ligas Ni-Cr-Mo com ou sem a adição do W $[4,7,8]$. A Figura 5 apresenta como exemplo a microestrutura observada no revestimento T65, no qual foi possível observar a evolução de todas as zonas de solidificação desde a interface da zona fundida (ZF) com o metal de base (MB) até o centro do revestimento.

Analisando a Figura 5, foi possível observar que a solidificação da matriz $\psi$-CFC deu início na forma planar por consequência do elevado gradiente térmico e da baixa velocidade de solidificação. Após a curta zona de crescimento planar, com a redução do gradiente térmico o metal de solda passou a solidificar no modo celular e, por fim, evoluiu para um crescimento colunar dendrítico, semelhante a resultados publicados na literatura [14].

A Figura 6 apresenta exemplos de microestruturas da zona fundida de cada um dos revestimentos. Nessas micrografias foi possível observar a presença de precipitados nas regiões interdendríticas. Estes precipitados são resultantes de elementos de liga segregados durante a solidificação fora do equilíbrio, que para estas condições de temperatura, pressão, resfriamento e composição química, se tornaram mais estáveis que a matriz. Além disso, a 
Efeito da Diluição Sobre a Microestrutura da Liga AWS ER NiCrMo-14 na Soldagem de Revestimentos pelo Processo TIG com Alimentação de Arame Frio

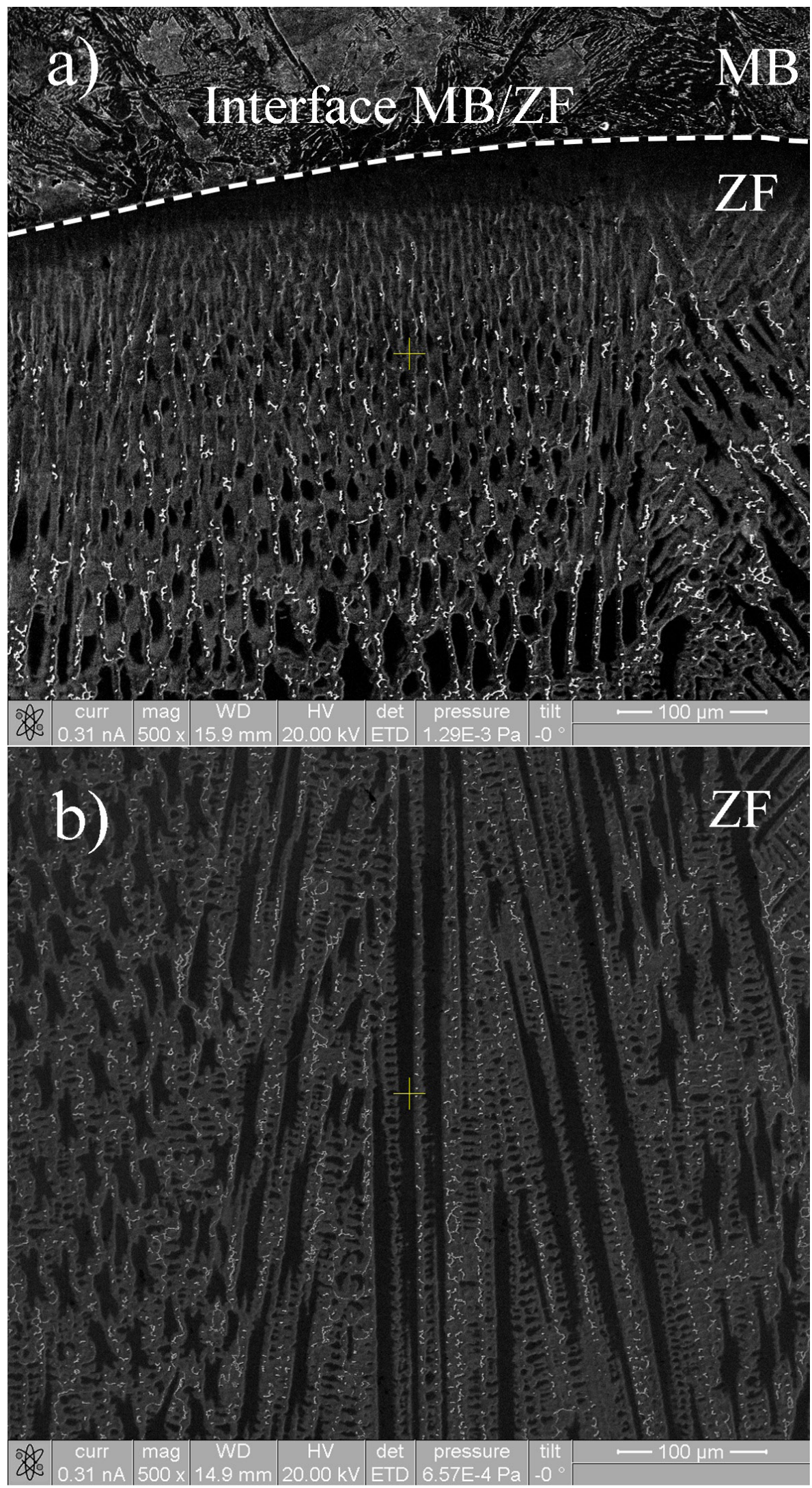

Figura 5. Microestrutura caracterizada no revestimento T65. (a) interface de solidificação seguida de um crescimento planar, celular e colunar dendrítico; (b) solidificação dendrítica observada no centro do revestimento. 

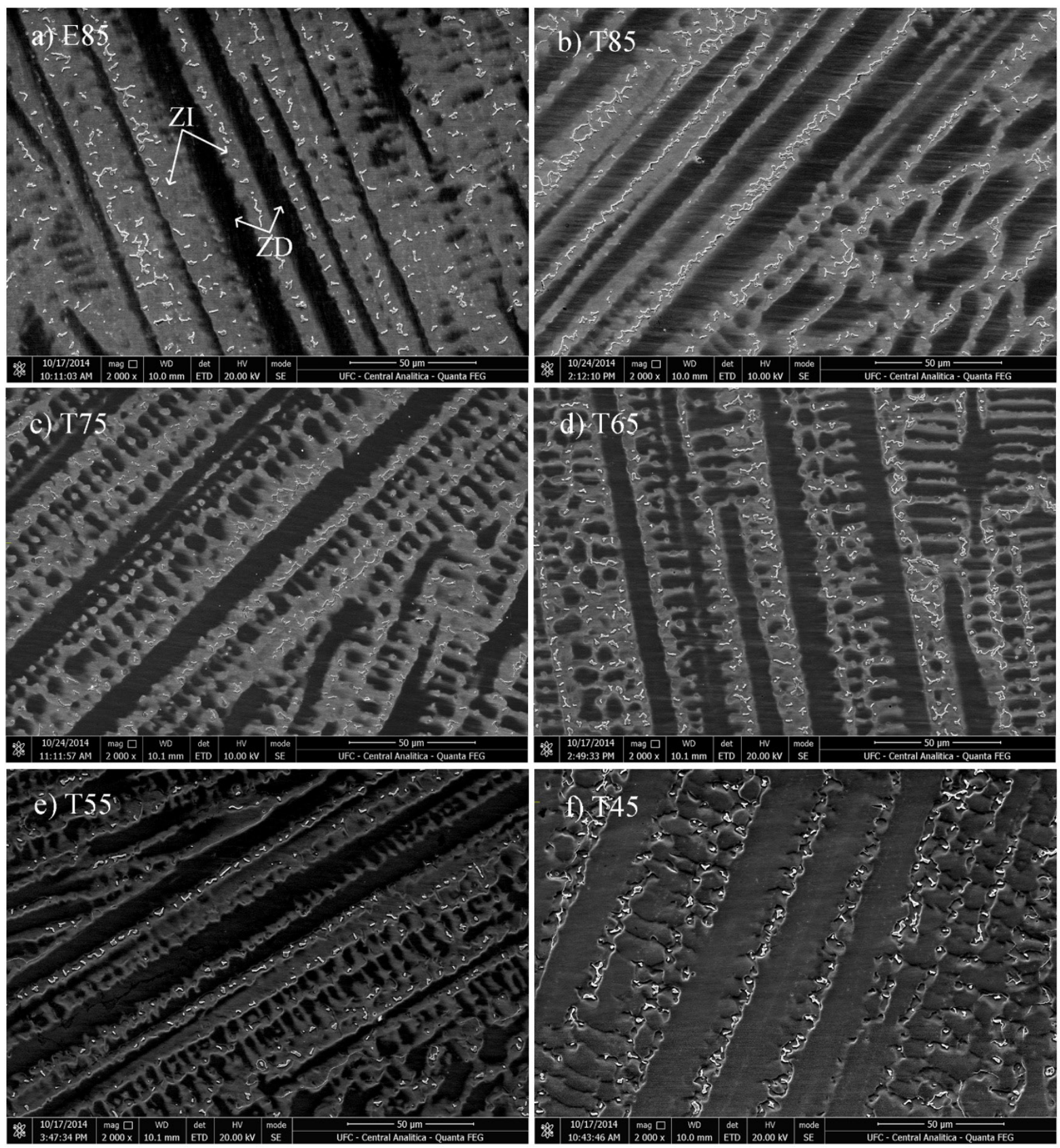

Figura 6. Exemplo de microestrutura observada no centro da zona fundida dos revestimentos: (a) E85; (b) T85; (c) T75; (d) T65; (e) T55 e (f) T45. ZD e ZI representam as zonas dendríticas e interdendríticas, respectivamente.

microestrutura da matriz $(\gamma)$ apresenta uma diferença de tonalidade entre as regiões dendrítica e interdendrítica, que pode ser consequência do gradiente químico promovido pela microssegregação durante a solidificação.

A Figura 7 apresenta um perfil de composição química de EDS obtido no revestimento T55. A varredura de EDS foi realizada ao longo de algumas dendritas e das suas respectivas regiões interdendríticas. Alguns elementos como o Ni e o Mo apresentaram alterações mais acentuadas. No caso do Ni, há um empobrecimento nas regiões interdendríticas, ao passo que o Mo apresenta um número de contagem maior na mesma região. Já o Fe apresentou uma pequena queda nas regiões interdendríticas. $\mathrm{O} \mathrm{Cr}$, assim como o Mo, apresentou um leve acréscimo no número de contagens. $\mathrm{O}$ W não apresentou alterações significativas nesta análise. Estas alterações microquímicas são consequências da microssegregação dos elementos de liga, que por sua vez favorecem a formação de fases 


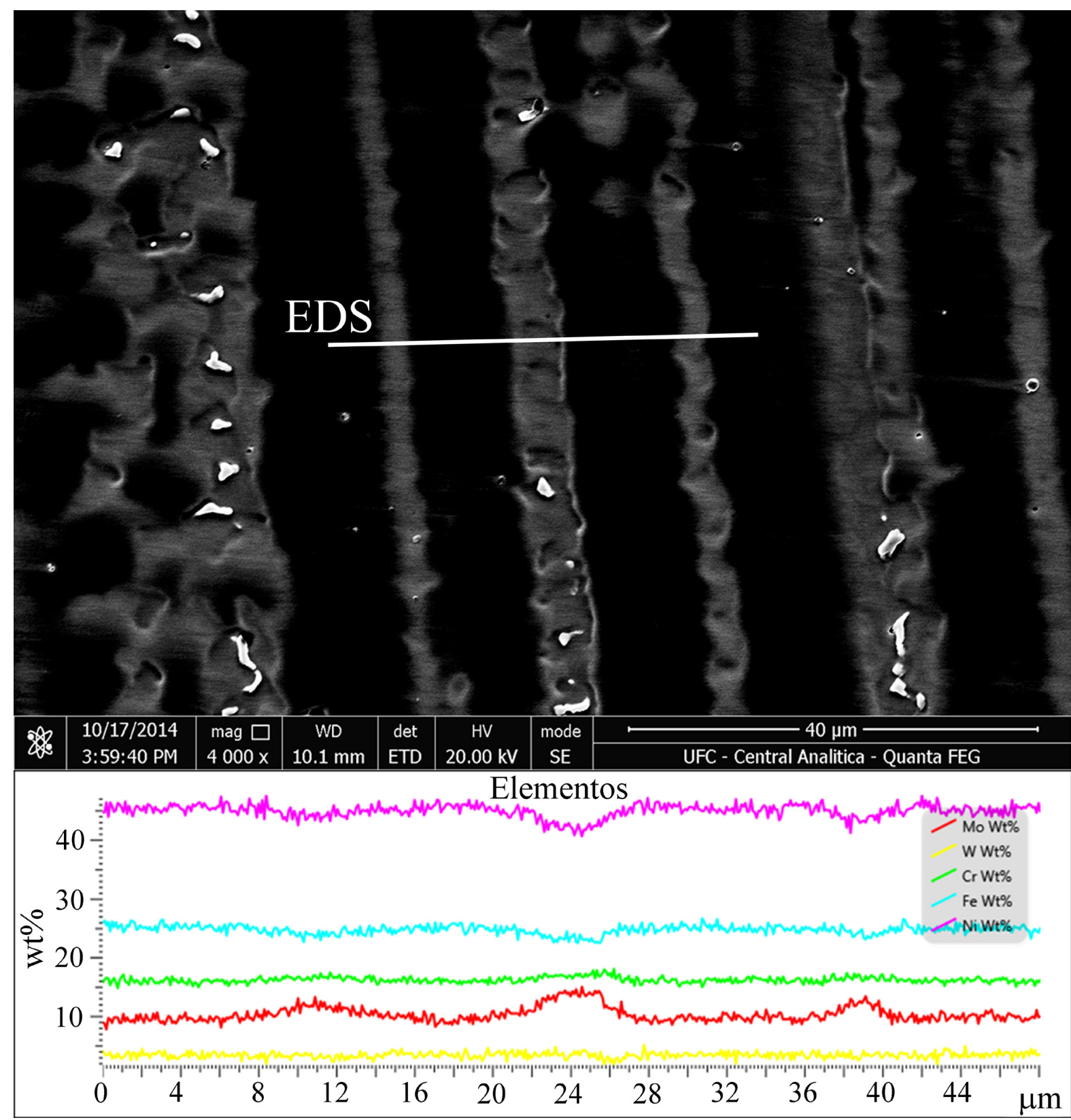

Figura 7. Varredura de composição química de EDS através das regiões dendrítica e interdendrítica localizadas na zona fundida do revestimento T55.

secundárias [5]. No caso das superligas de níquel, normalmente, são denominadas como fases topologicamente compactas ou fases TCP (topologically close-packed). Para ligas ricas em Cr e Mo, as fases TCP mais comuns são as fases $\sigma$, P e $\mu[4,5,7,8,15]$. Stockdale et al. [16] observaram que a diminuição da concentração de Mo influenciou diretamente na resistência à corrosão de equipamentos fabricados com liga inoxidável superaustenítica que foram reparadas com depósitos de liga Inconel 686.

A microssegregação observada nas Figuras 6 e 7, normalmente, está associada a perdas na soldabilidade, a alterações na temperatura de solidificação e à formação de fases secundárias [5]. Além disso, estas fases deletérias provocam regiões suscetíveis a corrosão na sua interface entre matriz e precipitado [4,7,8,14]. Miná et al. [17] avaliaram o efeito da diluição na microssegregação em revestimentos de liga Inconel 686. Os resultados mostraram haver alterações relevantes na microssegregação de alguns elementos de liga. Mais informações quanto ao efeito 
da diluição na microssegregação de revestimentos dissimilares com a liga Inconel 686 podem ser encontrados no referido estudo [17].

Com relação aos precipitados, eles apresentaram formas distintas em uma fração supostamente diferente. Duas morfologias foram observadas em todos os níveis de diluição. A primeira delas e a mais abundante é a morfologia disforme, que apresenta este aspecto por consequência do seu baixo ponto de fusão, ou seja, por ser o último volume líquido de liga na zona fundida, a sua solidificação se dá no pouco volume que lhes resta no interior da zona interdendrítica. $O$ segundo é um precipitado com aspecto de filmes, que normalmente são observados nos contornos de grão de solidificação, muitas vezes conectados a outros precipitados disformes. A precipitação do tipo filme é resultado do enriquecimento de elementos químicos segregados durante a solidificação, ou até mesmo pela difusão dos elementos durante o reaquecimento entre os passes. A Figura 8 apresenta os precipitados disformes e do tipo filme com maiores detalhes. Estas duas morfologias de precipitados já foram observadas em diversos trabalhos utilizando ligas $\mathrm{Ni}-\mathrm{Cr}-\mathrm{Mo}$, nos quais os autores destacam que possivelmente são fases TCP [4,7]. A identificação destes precipitados requer técnicas mais avançadas de microscopia, uma vez que a composição química observada por EDS destaca que estas fases são quimicamente semelhantes, sendo assim, necessário uso da difração de elétrons para distingui-las através das diferenças cristalográficas, já que a fase $\sigma$ é tetragonal [18,19], a fase P [20] é ortorrômbica e a fase $\mu$ é romboédrica [21,22].

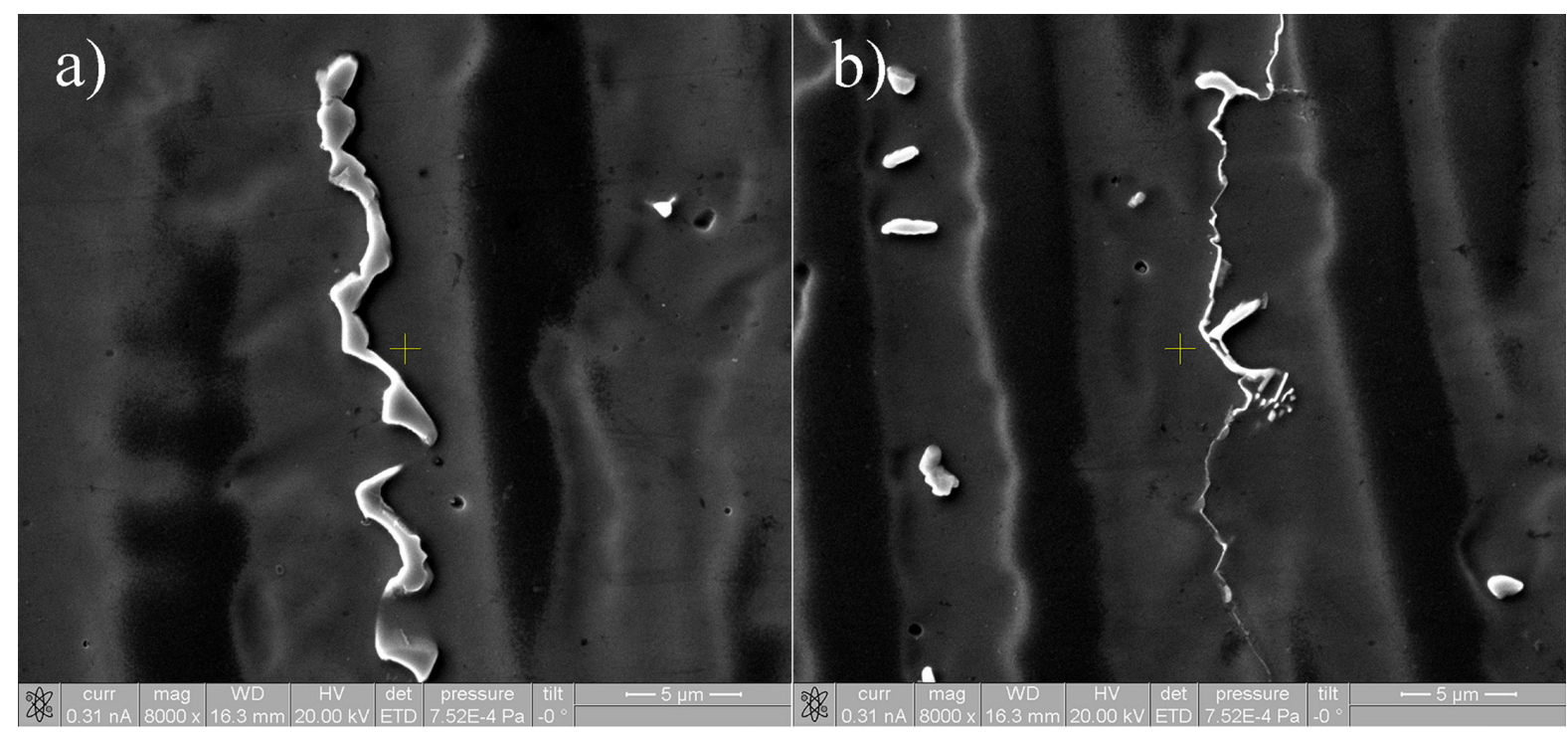

Figura 8. Micrografias obtidas do revestimento T65, nas quais foram observadas a precipitação com (a) morfologia disformes; (b) e do tipo filme.

Também foi observado um precipitado com aparência lamelar nos revestimentos E85 e T85, portanto, apenas nos revestimentos de menor diluição. A Figura 9 apresenta micrografias de fases lamelares observadas no revestimento E85. Esta morfologia foi relatada no trabalho de Silva [7], no qual o autor destacou uma possível orientação de crescimento a $45^{\circ} \mathrm{com}$ relação a direção de solidificação das dendritas. Nystrom et al. [23] estudaram superligas de níquel ricas em Re, e observaram colônias de fase $\mathrm{P}$ na forma de lamelas que se alternavam com a matriz, com um aspecto semelhantes aos precipitados observados no presente estudo. Os autores também destacaram que estas fases apresentavam uma orientação de crescimento de aproximadamente $45^{\circ} \mathrm{com}$ a direção [100] [23]. Apesar de não se tratar da mesma liga, a semelhança que há entre a morfologia e a sua orientação cristalográfica remetem a possibilidade de serem a mesma fase.

Foi possível observar que, normalmente, ao redor das fases lamelares há a presença de fases disformes ou do tipo filme. Ainda assim, não foi possível concluir se há alguma relação de crescimento entre elas. Como se 


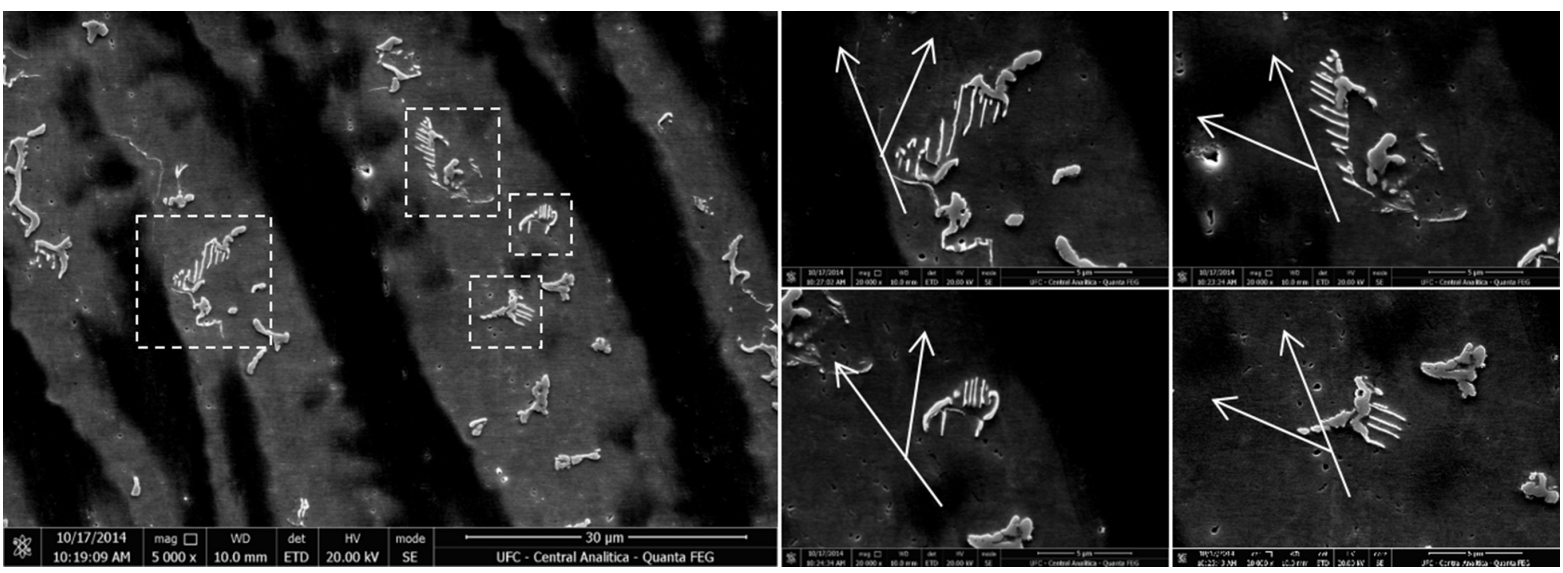

Figura 9. Microestruturas da zona fundida do revestimento E85, com fases lamelares próxima a outras fases disformes, com uma orientação de crescimento de aproximadamente $45^{\circ} \mathrm{com}$ a direção de solidificação.

trata de fases observadas apenas nos revestimentos de baixa diluição e, consequentemente, em revestimentos com um percentual de Fe de até aproximadamente 12\%, além de teores mais elevados dos elementos de liga ( $C r$ Mo e W), acredita-se que a sua formação é consequência da composição química mais favorável. Desse modo, há duas hipóteses prováveis, a primeira considera que estas fases sejam uma transformação eutética, ou seja, a liga no estado líquido se transformou em dois sólidos, sendo assim um produto da solidificação por consequência do enriquecimento de elementos de liga na região interdendrítica. Já a segunda hipótese é referente a uma transformação no estado sólido, por consequência do reaquecimento promovido pela soldagem multipasses. Contudo, não foi possível afirmar se houve uma reação eutética ou uma transformação no estado sólido.

Ainda com relação à hipótese de que a fase lamelar se trata de uma transformação no estado sólido, Silva [7] observou protuberância ao longo das bordas dos precipitados do tipo filme presentes nos contornos de grão na zona fundida de depósitos de uma superliga Ni-Cr-Mo-W, sendo assim possivelmente o crescimento da mesma ou de uma outra precipitação. $\mathrm{O}$ autor destacou que estas protuberâncias deveriam estar relacionadas com a energia fornecida pelo reaquecimento dos passes durante a deposição do revestimento. Esta hipótese só reforça a possibilidade de que a fase lamelar seja produto de uma transformação de fases no estado sólido. Outra questão ficaria por conta da decomposição ocorrida durante a transformação de fase, que poderia ser tanto da matriz como dos precipitados. Ainda analisando as protuberâncias observada ao longo dos contornos de grãos no estudo de Silva [7], o crescimento junto aos precipitados pode ser um indicativo de que houve uma decomposição da matriz para a formação de uma outra fase [7].

Uma quarta morfologia de fase secundária foi observada nos revestimentos mais diluídos. Precipitados disformes, desta vez com a presença finos precipitados agregados, que podem estar na superfície e/ou no interior do precipitado disforme. Estas fases foram identificadas apenas nas condições T55 e T45, que apresentam teores de Fe acima de $27 \%$. No revestimento T55, essas fases foram identificadas com menor frequência se comparado ao revestimento mais diluído, desse modo, o teor de Fe mais elevado e, consequentemente, uma fração menor de elementos $\mathrm{Cr}$, Ni, Mo e W podendo estar relacionados na nucleação destas fases. A Figura 10 apresenta uma micrografia que destaca a fina precipitação agregada a fase disforme.

Perricone e Dupont [24] avaliaram superligas de níquel fundida e puderam observar a presença de uma precipitação com morfologia semelhante à observada na Figura 10 na liga experimental com elevado teor de Fe, 43Fe-24Ni-20Cr-12Mo. Os autores concluíram após uma análise de difração de elétrons, que o precipitado se tratava de uma fase eutética composta por fase $\sigma$ com ilhas de fase $\gamma$ no seu interior. Os autores ainda destacaram o efeito do Fe no campo de estabilidade da fase $\sigma$, que naturalmente foi ampliada com o seu aumento percentual na liga [24]. Outros trabalhos, que avaliaram depósitos da liga 686, relataram a presença da fase $\sigma$ observada em experimentos de difração de raios-X aplicada em pós dos precipitados extraídos do metal de solda [4,7]. 


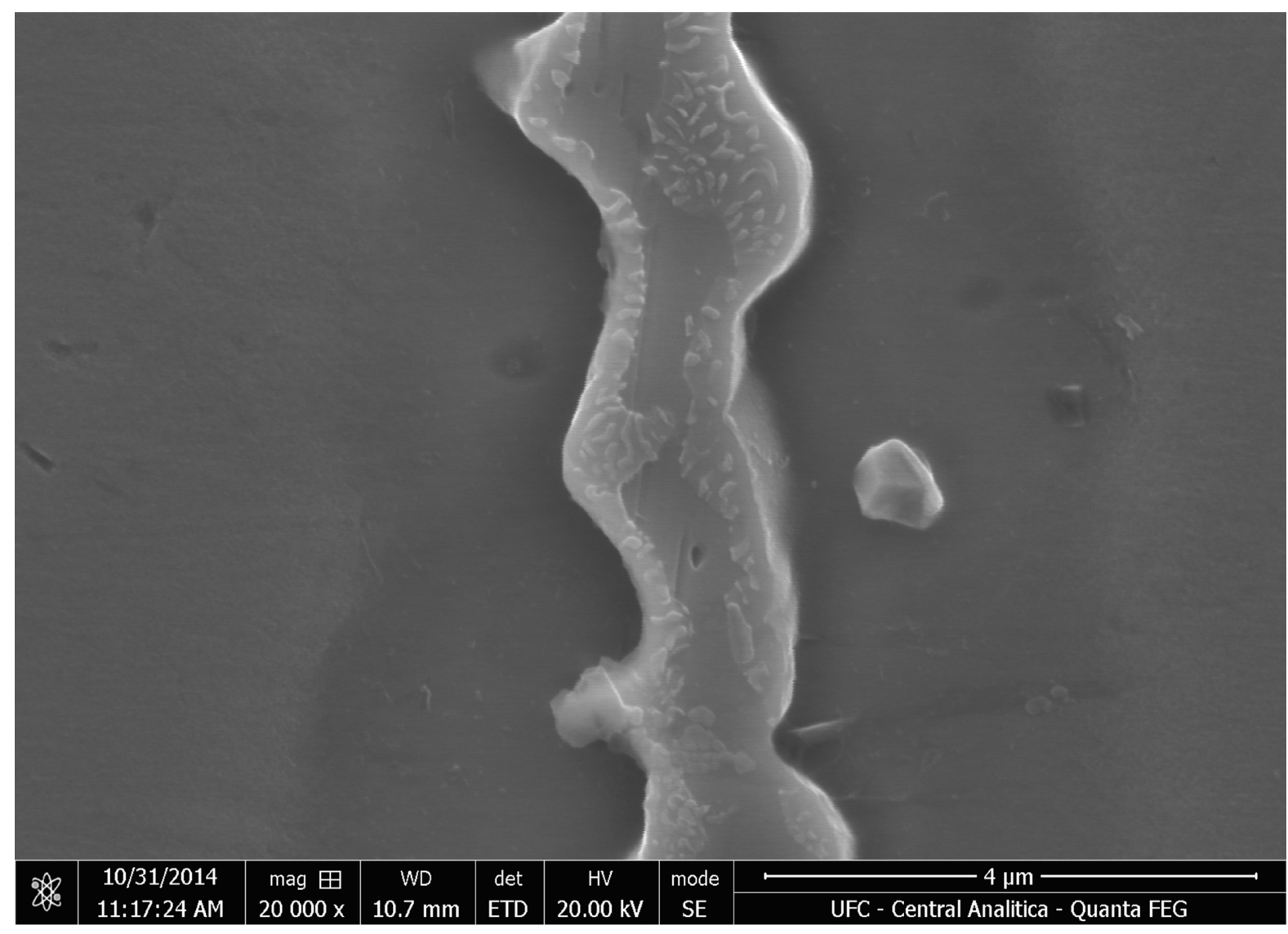

Figura 10. Fase disforme com uma fina precipitação agregada na sua superfície e/ou no seu interior.

\section{Conclusão}

Com base nos resultados experimentais obtidos no presente estudo sobre revestimentos dissimilares soldados pelo processo TIG com alimentação de arame frio da liga AWS ERNiCrMo-14 (Inconel 686), com diversos níveis de diluição, no qual foi avaliado a microestrutura, foi possível concluir que:

A microestrutura da zona fundida em todos os níveis de diluição foi composta por dendritas de fase $y$-CFC alternadas com regiões interdendríticas ricas em elementos de liga, com a presença de precipitados de fases topologicamente compactas (TCP).

A microssegregação de elementos de liga foi evidenciada nas regiões interdendríticas, promovendo regiões distintas de resistência a corrosão.

O precipitado com morfologia disforme foi a fase secundária mais abundante observada na zona fundida em todas os revestimentos. A sua peculiar morfologia é consequência do seu baixo ponto fusão, que ao solidificar preserva o formato do metal liquido remanescente entre as dendritas.

Foi observada uma precipitação ao longo dos contornos de grãos de solidificação com um aspecto de filme. Estes precipitados foram caracterizados para todos os níveis de diluição e possivelmente são resultados de uma transformação de fases após a reaquecimento entre os passes na soldagem do revestimento.

Um tipo de precipitação lamelar, que possivelmente seja fase $P$, foi observada apenas nos revestimentos de menor diluição. Foi observada uma possível relação de orientação de crescimento das lamelas a $45^{\circ} \operatorname{com}$ a direção [100].

Foi observada nos revestimentos de maior diluição, uma precipitação disforme com uma fina precipitação agregada, que possivelmente seja fase $\sigma$. 
Efeito da Diluição Sobre a Microestrutura da Liga AWS ER NiCrMo-14 na Soldagem de Revestimentos pelo

Processo TIG com Alimentação de Arame Frio

\section{Agradecimentos}

Os autores gostariam de agradecer ao Laboratório de Pesquisa e Tecnologia em Soldagem (LPTS) da Universidade Federal do Ceará (UFC), e à Central Analítica da UFC projeto CT-INFRA/MCTI-SISNANO/PRÓ-EQUIPAMENTOS CAPES, por conceder a utilização do seu microscópio eletrônico de varredura para a realização de análises. E aos órgãos PETROBRAS, FUNCAP, CNPq, FINEP e CAPES que financiaram este estudo com suporte financeiro e concessão de bolsas de graduação e mestrado.

\section{Referências}

[1] Hodge FG. The history of solid-solution-strengthened Ni alloys for aqueous corrosion service. JOM. 2006;58(9):28-31. http:// dx.doi.org/10.1007/s11837-006-0078-9.

[2] Deacon RM, Dupont JN, Marder AR. High temperature corrosion resistance of candidate nickel-based weld overlay alloys in a low NOx environment. Materials Science and Engineering A. 2007;460461:392-402. http://dx.doi.org/10.1016/j.msea.2007.01.150.

[3] Silva CC, Afonso CRM, Ramirez AJ, Motta MF, Miranda HC, Farias JP. Aspectos metalúrgicos de revestimentos dissimilares com a superliga à base de níquel inconel 625 . Soldagem \& Inspeção. 2012;17:251-263.

[4] Aguiar WM. Revestimento por soldagem MIG/MAG empregando ligas de níquel para aplicações em componentes soldados do setor de petróleo e gás natural [tese de doutorado]. Fortaleza: Universidade Federal do Ceará; 2010. 255 p.

[5] Dupont JN. Solidification of an alloy 625 weld overlay. Metallurgical and Materials Transactions A, Physical Metallurgy and Materials Science. 1996;27(11):3612-3620. http://dx.doi.org/10.1007/ BF02595452.

[6] Silva CC, Miranda HC, Motta MF, Farias JP, Afonso CRM, Ramirez AJ. New insight on the solidification path of an alloy 625 weld overlay. Journal of Materials Research and Technology. 2013;2(3):228-237. http://dx.doi.org/10.1016/j.jmrt.2013.02.008.

[7] Silva CC. Revestimentos de ligas de níquel depositadas pelo processo TIG com alimentação de arame frio - aspectos operacionais e metalúrgicos [tese de doutorado]. Fortaleza: Universidade Federal do Ceará; 2010. 319 p.

[8] Silva CC, Afonso CRM, Miranda HC, Ramirez AJ. Migração de Molibdênio na Interface Matriz/Precipitado em Metais de Solda de Ligas Ni-Cr-Mo. Tecnologia em Metalurgia Materiais e Mineração. 2011;8(3):197-202.

[9] Ahn Y, Yoon B, Kim H, Lee C. Effect of dilution on the behavior of solidification cracking in PTAW overlay deposit on Ni-Base superalloys. Metals and Materials International. 2002;8(5):469477. http://dx.doi.org/10.1007/BF03027245.

[10] Banovic SW, Dupont JN, Marder AR. Dilution control in gas-tungsten-arc welds involving superaustenitic stainless steels and nickel-based alloys. Metallurgical and Materials Transactions B, Process Metallurgy and Materials Processing Science. 2001;32(6):1171-1176. http://dx.doi.org/10.1007/ s11663-001-0104-9.

[11] Banovic SW, Dupont JN, Marder AR. Dilution and microsegregation in dissimilar metal welds between super austenitic stainless steel and nickel base alloys. Science and Technology of Welding and Joining. 2002;7(6):374-383. http://dx.doi. org/10.1179/136217102225006804.

[12] Miranda EC, Silva CC, Motta MF, Miranda HC, Farias JP. Avaliação do Uso do tecimento sobre o nível de diluição e geometria do cordão de solda na soldagem TIG com alimentação automática de arame frio. Soldagem \& Inspeção. 2015;20(2):180-190.
[13] Silva CC, Miranda EC, Motta MF, Miranda HC, Farias JP. Minimização de defeitos em revestimentos de superligas de níquel depositada pelo processo TIG com alimentação de arame frio. Soldagem \& Inspeção. 2014;19(4):323-332.

[14] Silva CC, Miranda HC, Farias JP, Abreu HFG. Chemistry and Crystallographic Evaluation of Ni-based Alloy and Steel Dissimilar Interface. In: Trends in Welding Research 2012: Proceedings of the 9th International Conference; 2012 Jun. 4-8; Chicago, USA. Ohio: ASM International; 2013. 344 p.

[15] Cieslak MJ, Headley TJ, Romig AD. The welding metallurgy of HASTELLOY alloys C-4, C-22, and C-276. Metallurgical Transactions A, Physical Metallurgy and Materials Science. 1986;17(11):20352047. http://dx.doi.org/10.1007/BF02645001.

[16] Stockdale AW, Dupont JN. Microstructural evolution and corrosion resistance of fusion welds on alloy CN3MN made with IN686 filler metal. Science and Technology of Welding and Joining. 2011;16(5):426-432. http://dx.doi.org/10.1179/1 $362171811 Y .0000000007$.

[17] Miná ÉM, Silva YC, Dille J, Silva CC. The effect of dilution on microsegregation in the AWS ER NiCrMo-14 alloy welding claddings. Metallurgical and Materials Transactions A. 2016 In press.

[18] Yakel H. Atom distributions in sigma phases. I. Fe and $\mathrm{Cr}$ atom distributions in a binary sigma phase equilibrated at 1063, 1013 and 923 K. Acta Crystallographica. Section B, Structural Crystallography and Crystal Chemistry. 1983;39(1):20-28. http:// dx.doi.org/10.1107/S0108768183001974.

[19] Joubert JM. Crystal chemistry and Calphad modeling of the $\sigma$ phase. Progress in Materials Science. 2008;53(3):528-583. http://dx.doi.org/10.1016/j.pmatsci.2007.04.001.

[20] Shoemaker DP, Shoemaker CB, Wilson FC. The crystal structure of the P phase, Mo-Ni-Cr. II. Refinement of parameters and discussion of atomic coordination. Acta Crystallographica. 1957;10(1):1-14. http://dx.doi.org/10.1107/S0365110X57000018.

[21] Forsyth JB, Veiga LMD. The structure of the [mu]-phase Co7Mo6. Acta Crystallographica. 1962;15(6):543-546. http://dx.doi. org/10.1107/S0365110X62001401.

[22] Joubert JM, Dupin N. Mixed site occupancies in the $\mu$ phase. Intermetallics. 2004;12(12):1373-1380. http://dx.doi.org/10.1016/j. intermet.2004.04.036.

[23] Nystrom JD, Pollock TM, Murphy WH, Garg A. Discontinuous cellular precipitation in a high-refractory nickel-base superalloy. Metallurgical and Materials Transactions A, Physical Metallurgy and Materials Science. 1997;28(12):2443-2452. http://dx.doi. org/10.1007/s11661-997-0001-1.

[24] Perricone MJ, Dupont JN. Effect of composition on the solidification behavior of several $\mathrm{Ni}-\mathrm{Cr}-\mathrm{Mo}$ and $\mathrm{Fe}-\mathrm{Ni}-\mathrm{Cr}-\mathrm{Mo}$ alloys. Metallurgical and Materials Transactions A, Physical Metallurgy and Materials Science. 2006;37(4):1267-1280. http:// dx.doi.org/10.1007/s11661-006-1078-7. 